\title{
IMPACT OF BROADBAND SEISMOLOGY ON THE UNDERSTANDING OF STRONG MOTIONS
}

\author{
Don Helmberger, Douglas Dreger, Richard Stead, \\ AND HIROO KaNAMORI
}

\begin{abstract}
Most analyses of strong motion attenuation assume simple whole-space type geometrical spreading, namely $(1 / R)$ or its modified form $e^{-k R / R}$. However, broadband data presently becoming available suggests a more complex behavior with substantial crustal effects. Events such as the Sierra Madre event, $M=5.8$, triggered the strong motion channels at all of the TERRAscope stations allowing for 0.01 -sec sampling of the wavefield. We find that most of the well-defined crustal bodywave arrivals defined and modeled in the 1 to 0.1-hz bandpass also contain high-frequency energy. By comparing the triggered channels with the continuous channels we see that several of the more distant stations triggered on the depth phase $s P_{m} P$. These phases as well as the depth phase ${ } S_{m} S$ are obvious in velocity and quite apparent in accelerations. Our best models for Southern California contain a relatively thick low-velocity layer at the surface, roughly $5 \mathrm{~km}$ thick with shear velocities below $3 \mathrm{~km} / \mathrm{sec}$. This layer or zone, because it appears to vary considerably, controls the wavefield at nearly all frequencies out to about $60 \mathrm{~km}$ and yields attenuation decay faster than (1/R). At larger ranges the lower crustal triplications dominate and the attenuation curve flattens. Adding random scatters to these layered models adds additional complexity but does not alter the basic flat-layer predictions.
\end{abstract}

\section{INTRODUCTION}

Amplitude decay or attenuation as defined by the strong-motion community has received a great deal of attention in recent years. Earlier strong-motion datasets were truncated at relatively small distances, typically around $70 \mathrm{~km}$. This seemed to be caused by the prevalent processing method, in which one truncates the range of interest at the first strong-motion station that failed to trigger. However, more complete datasets such as those produced from the Loma Prieta earthquake, show strong evidence for a flattening and a possible increase in amplitude near a distance of $100 \mathrm{~km}$ Campbell, 1991 and Somerville and Yoshimura 1990. The latter study suggested that reflections from the Moho discontinuity was responsible for this effect. Weak-motion observations from aftershocks seem to confirm the "Moho-reflected hypothesis" as reported by McGarr et al. (1991). The relatively thin crustal thickness and relatively large source depth in this region are apparently the reasons for the shift in Moho phases to nearer distances. However, given the scattered nature of the amplitudes produced by the relatively narrowband conventional strong-motion instruments, it proves difficult to resolve these issues. Fortunately, the recently installed TERRAscope array is providing the ideal data to address the role of the crust in strong-motion generation. In particular, we can now examine the broadband wavefield for relatively strong earthquakes and their aftershocks along similar paths. Thus, the Sierra Madre earthquake, $M=5.8$, has been recorded well enough to examine displacements, velocities, and accelerations 
with little concern about instrumental distortions. Moreover, we find that the displacement field can be relatively well explained with standard Southern California travel time models, at least at long periods. Such models indicate a cross-over in distance at about $130 \mathrm{~km}$, where ray paths bottoming in the lower crust become the first arrivals. By comparing the observed broadband records with the strong motions, we find that the critical angles identified for 1-sec signals correspond with the timing of strong high-frequency arrivals. This paper is primarily concerned with characterizing the seismic paths at these ranges, 20 to $160 \mathrm{~km}$, and their associations with the complete field of motion.

The data analyzed in this report were produced by the well-studied Sierra Madre earthquake of 28 June 1991 (Dreger and Helmberger, 1991a; Wald; 1992). The latter study indicates that this event was relatively high-stress drop, and thus an appropriate source for studying the attenuation of the strong-motion field. Figure 1 displays the locations of the existing TERRAscope array stations in which the event proves to be equidistant to four of the stations (Table 1). A comparison of the displacements produced by these stations with corresponding synthetics is given in Figure 2. The waveform data are plotted in absolute time, whereas the synthetics appropriate for a SoCal velocity model A (Table 2) have been delayed by $0.35 \mathrm{sec}$ for alignment with the first arrivals. Arrival times of $P_{n}$ (mantle headwave), $P_{m} P$ and $S_{m} S$ (reflection from the Moho), and the depth phase $s P_{m} P$ appropriate for model SoCal are indicated. The phase marked $P_{n}$ is near the critical angle, so the Moho reflection, $P_{m} P$, dominates the associated

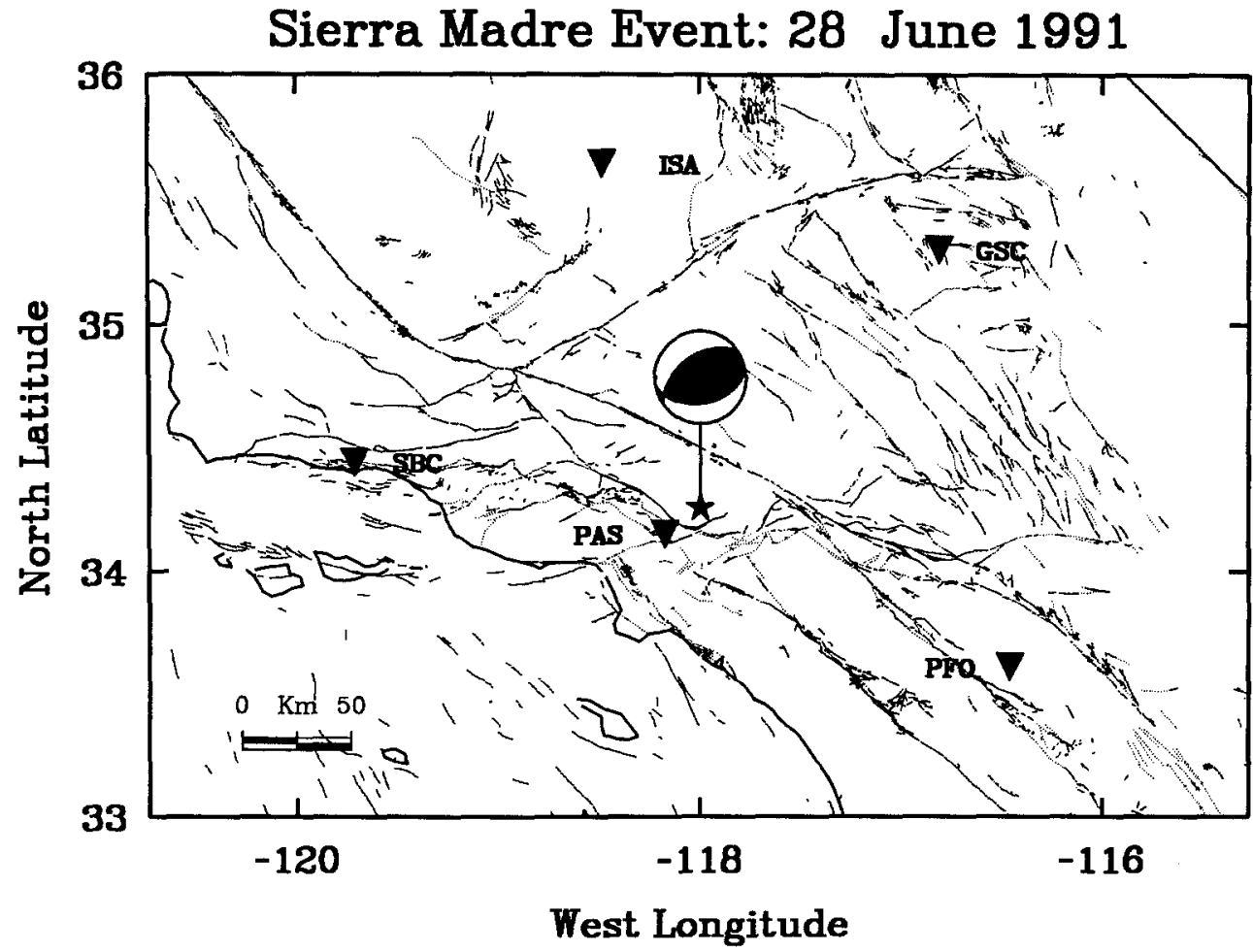

FIG. 1. Map of Southern California showing the locations of the TERRAscope stations and the Sierra Madre event indicated by the star. Note that four of the stations are essentially at the same range of $160 \mathrm{~km}$ : GSC, ISA, PFO, and SBC. 
TABLE 1

TERRAscope Station Locations

\begin{tabular}{lcccc}
\hline Station & $\begin{array}{c}\text { Latitude } \\
(\mathrm{n})\end{array}$ & $\begin{array}{c}\text { Longitude } \\
(\mathrm{w})\end{array}$ & $\begin{array}{c}\text { Distance } \\
(\mathrm{km})\end{array}$ & Azimuth* \\
\hline GSC & 35.300 & 116.810 & 158.2 & 44 \\
ISA & 35.643 & 118.480 & 159.6 & 344 \\
PAS & 34.148 & 118.172 & 20.6 & 232 \\
PFO & 33.609 & 116.455 & 159.6 & 117 \\
SBC & 34.442 & 119.713 & 159.4 & 277 \\
\hline
\end{tabular}

* Azimuth to the station in degrees.

Comparison of Broadband Data and Synthetics

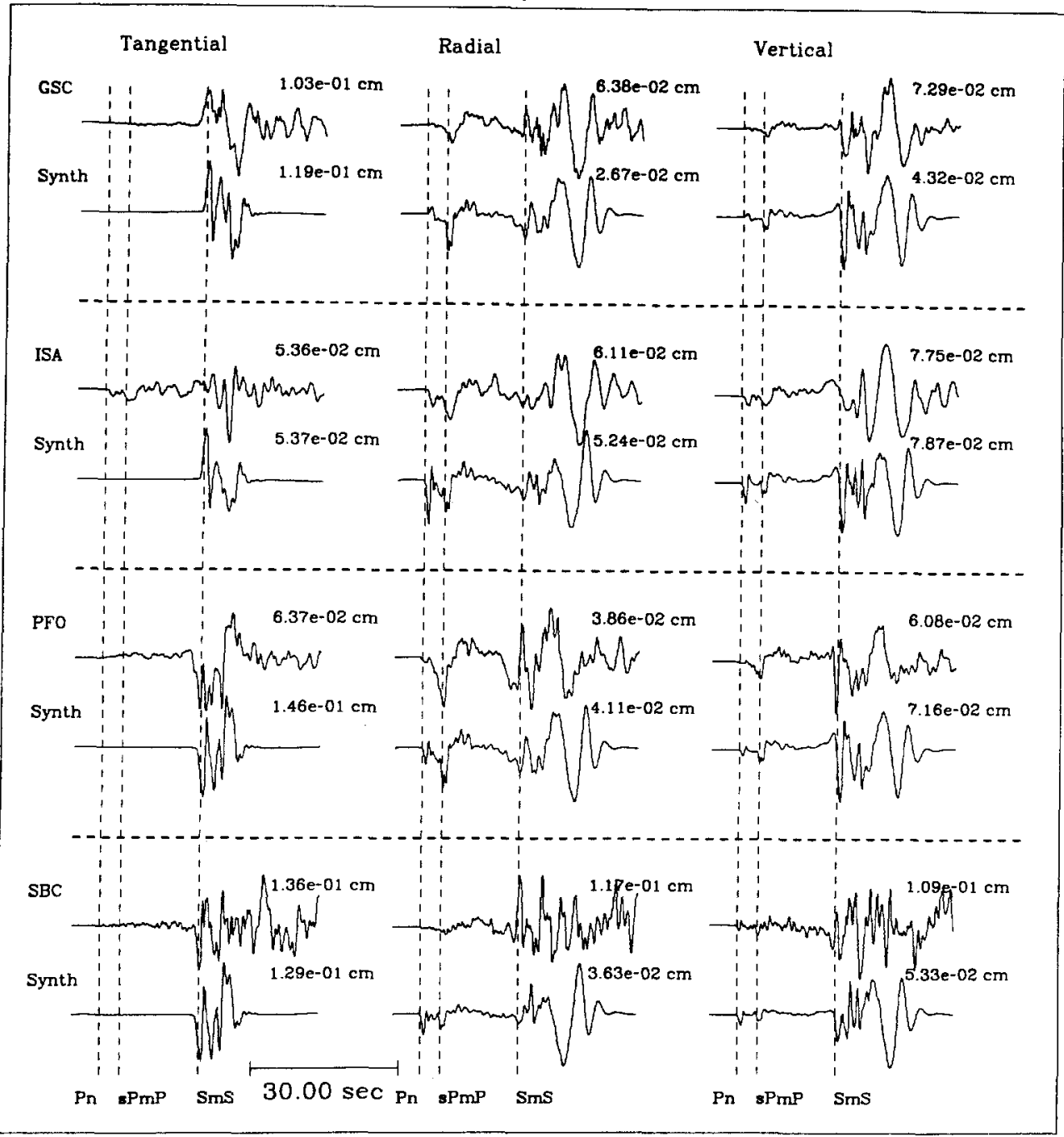

FTG. 2. Comparison of the broadband displacement data with corresponding synthetics. Peak amplitudes are expressed in $\mathrm{cm} . P_{n}$ indicates the mantle arrival. The reflections from the crustmantle interface are labeled $s P_{m} P$ and $S_{m} S$, respectively. 
TABLE 2

\begin{tabular}{ccccr}
\multicolumn{5}{c}{ CRUSTAL ModeLS } \\
\hline Station & $\begin{array}{c}\mathrm{V}_{\mathrm{p}} \\
(\mathrm{km} / \mathrm{sec})\end{array}$ & $\begin{array}{c}\mathrm{V}_{\mathrm{s}} \\
(\mathrm{km} / \mathrm{sec})\end{array}$ & $\begin{array}{c}\rho \\
(\mathrm{g} / \mathrm{cc})\end{array}$ & $\begin{array}{c}\mathrm{Th} \\
(\mathrm{km})\end{array}$ \\
\hline $\mathrm{A}$ & 5.5 & 3.18 & 2.4 & 5.5 \\
& 6.3 & 3.64 & 2.67 & 10.5 \\
& 6.7 & 3.87 & 2.8 & 19.0 \\
$\mathrm{~B}$ & 7.8 & 4.5 & 3.0 & - \\
& 5.5 & 3.0 & 2.4 & 5.5 \\
& 6.3 & 3.6 & 2.6 & 9.5 \\
& 6.7 & 3.8 & 2.8 & 19.0 \\
& 7.8 & 4.3 & 3.0 & 5.0 \\
$\mathrm{C}$ & 7.85 & 4.4 & 3.4 & \\
& 3.8 & 1.98 & 2.3 & 1.5 \\
& 5.5 & 3.15 & 2.6 & 2.5 \\
& 6.2 & 3.52 & 2.7 & 22.0 \\
& 6.8 & 3.83 & 2.87 & 6.0 \\
$\mathrm{D}$ & 8.3 & 4.6 & 3.36 & \\
& 5.4 & 3.2 & 2.7 & 4.0 \\
& 6.2 & 3.6 & 2.85 & 16.0 \\
& 6.6 & 3.75 & 3.2 & 8.0 \\
& 7.5 & 4.1 & 3.42 & 3.0 \\
& 7.8 & 4.25 & 3.45 & \\
\hline
\end{tabular}

pulse at least at short periods. Remarkably, the observed variations in the travel times of these moho reflection phases are less than $3 \%$. However, the surface waves show considerably more scatter; this is especially true for the SBC station where the observed Love wave appears to be at least $10 \mathrm{sec}$ late. The Rayleigh wave fit is quite good at station GSC, but somewhat misaligned in timing at stations ISA and PFO. It appears that some model adjustments of shallow structure for these three paths could bring these synthetic surface waveforms into better agreement with the data, but there are some obvious advantages in working with a $1 \mathrm{D}$ model. Because the bodywaves appear more stable in timing, we can truncate the waveforms just before the surface waves and use the relative strengths of the various pulses, $S_{m} S$ to $s S_{m} S$ etc., to determine source characteristics. If we further smooth these observations by convolving with a long period filter, we find that the small differences in timing can be neglected and a direct waveform inversion technique can be applied. A moment of $2.5 \times 10^{24}$ dyne-cm and the fault orientation parameters, strike $=$ $235^{\circ}$, rake $-74^{\circ}$, and $\operatorname{dip}=50^{\circ}$, used in computing these synthetics, were obtained from a long-period source inversion such as is discussed by Dreger and Helmberger (1991a). The above orientation and moment are in excellent agreement with strong-motion waveform and teleseismic data as inverted by Wald (1992). The latter study produced a distributed fault model in which the rupture propagated up and to the southwest. A similar picture is obtained by comparing the aftershocks with the mainshock on the TERRAscope array (Dreger and Helmberger, 1992).

Although directivity has a strong effect on the analysis of the motion, as discussed in the above paper, we will assume a simple point source in this study and concentrate on path effects. Thus, we assume a triangular time history, 0.5 sec up and 0.5 sec down, for the far-field displacement pulse as deduced by 
Dreger and Helmberger (1991a). This was the time history used in generating the synthetics displayed in Figure 2.

In the next section, we introduce the broadband velocities and accelerations. This is followed by a discussion of forward-modeling attempts involving flatlayered models and the properties of the crustal waveguides. Following this, we introduce random scatterers into the various layers and investigate their contributions to the wavefield and their impact on amplitude attenuation.

\section{Velocity and Acceleration Data}

The TERRAscope system operates in two modes: one samples every $0.05 \mathrm{sec}$ continuously, while the other is triggered and samples every $0.01 \mathrm{sec}$. This is accomplished by employing two types of sensors, Streckeisen STS-1 for the very broadband (vbb) channel, and Kinemetrics FBA-23 for the low-grain (lg) channel. For the Pasadena station, the displacement response of the vbb channel with a Quanterra 24-bit digitizer is given as a function of frequency $f$ by

$$
I(f)=2 \pi i f^{3} G /\left[f^{2}-2 i h f_{0} f-f_{0}^{2}\right]
$$

where $f_{0}=0.00278 \mathrm{~Hz}, h=0.707$, and $G=1.04 \times 10^{7}$ counts $/(\mathrm{cm} / \mathrm{sec})$. At frequencies higher than $7 \mathrm{~Hz}$, and anti-alias filter with an $f^{-2}$ roll-off is applied. This response is approximately flat for ground-motion velocity over a frequency range of $7 \mathrm{~Hz}$ to $0.0033 \mathrm{~Hz}(300 \mathrm{sec})$. This channel is digitized at 20 samples/sec.

The displacement response of the $\mathrm{lg}$ system with a Quanterra 16-bit digitizer is given by

$$
I(f)=4 \pi^{2} f_{0}^{2} f^{2} G /\left[f^{2}-2 i h f_{0} f-f_{0}^{2}\right]
$$

where $f_{0}=50 \mathrm{~Hz}, h=0.7$, and $G=37.38$ counts $/\left(\mathrm{cm} / \mathrm{sec}^{2}\right)$. This response is approximately flat for a ground-motion acceleration at frequencies lower than $20 \mathrm{~Hz}$. This channel is digitized at 100 samples $/ \mathrm{sec}$.

The deconvolution of the instrument response for the vbb channel is usually performed on the frequency domain using (1). For the lg channel, deconvolution is performed either on the frequency domain using (2) or in the time domain by doubly integrating the acceleration trace. The gain factors at stations other than Pasadena are within $10 \%$ of that for Pasadena; detailed constants are published in Wald et al. (1991).

The calibration of the entire system has been performed whenever a large amplitude motion was recorded with both STS-1 and FAB-23. We do not calibrate the shape of the response curve, but calibrate the gain factor by comparing the amplitudes recorded with STS-1 and FBA-23. The response is very stable, and we believe that the overall gain is accurate within $5 \%$.

On the top three rows of Figures 3,4,5, and 6 are the vbb responses (continuous sample) and on the bottom three rows are the $\mathrm{lg}$ responses (triggered). The velocities are essentially identical, which demonstrates the calibration stability. The accelerations are somewhat different as a result of the sampling differences, but the depth phases are still apparent on the velocity times histories, as indicated by the dotted lines. It appears that most of $\mathrm{lg}$ channels triggered on the phase $s P_{m} P$. Unfortunately, some of the beginning 

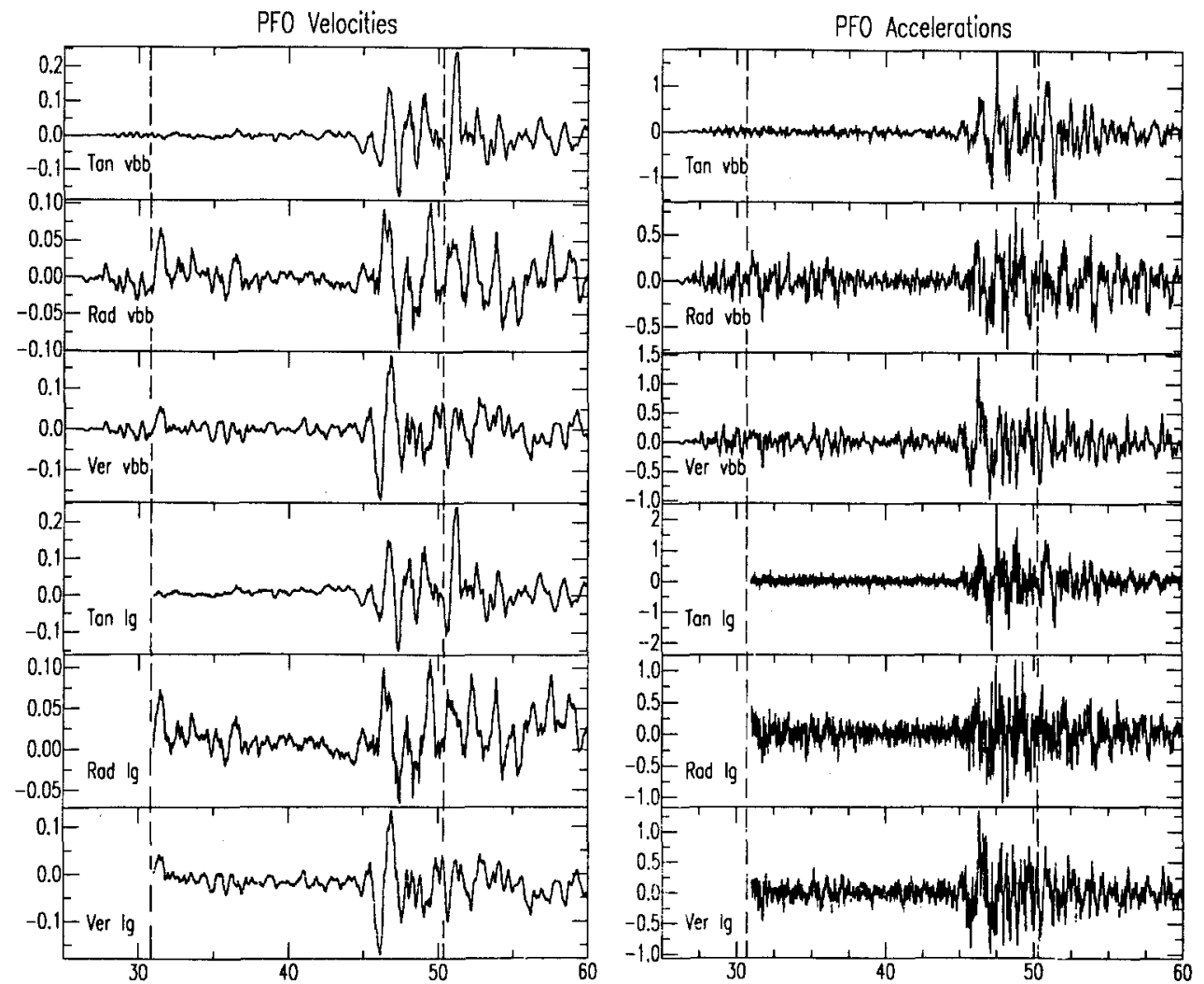

FIG. 3. Comparison of the observed velocities and accelerations at PFO, generated by taking the derivative of (vbb) and by integrating (lg).

portions of the wavetrain were lost due to bugs in a new system (see Figures 4 and 6).

\section{Crustal Structure and Path Contributions}

We begin by convolving the observed broadband data through a series of instrumental responses, as shown in Figures 7 and 8. These three instruments have recorded data in Pasadena for many years, and comparing TERRAscope data with the existing dataset provides highly useful, as reported by Helmberger et al. (1992). Note that although the surface waves are quite prominent on the long period Press-Ewing (3090) in Figure 7, they are not apparent on the conventional Wood-Anderson (WASP). The intermediate channel, or WALP (long period Wood-Anderson), contains some arrivals associated with surface waves and body waves. Included in these figures are the motions produced by a magnitude 4.2 aftershock (28 June, 1700UT). The aftershock has a slightly different mechanism which enhances the phase $P_{m} P$ in Figure 7 as is particularly apparent in the WALP bandpass (see Zhao and Helmberger, 1993). The similarity between the mainshock and aftershock observed in these figures is, also, apparent at the other stations indicating the deterministic nature of the wavefield. The 3090 response is relatively easy to match with synthetics from standard models, whereas the WASP data is more difficult. However, it appears that all three responses can be explained to some degree with some small 

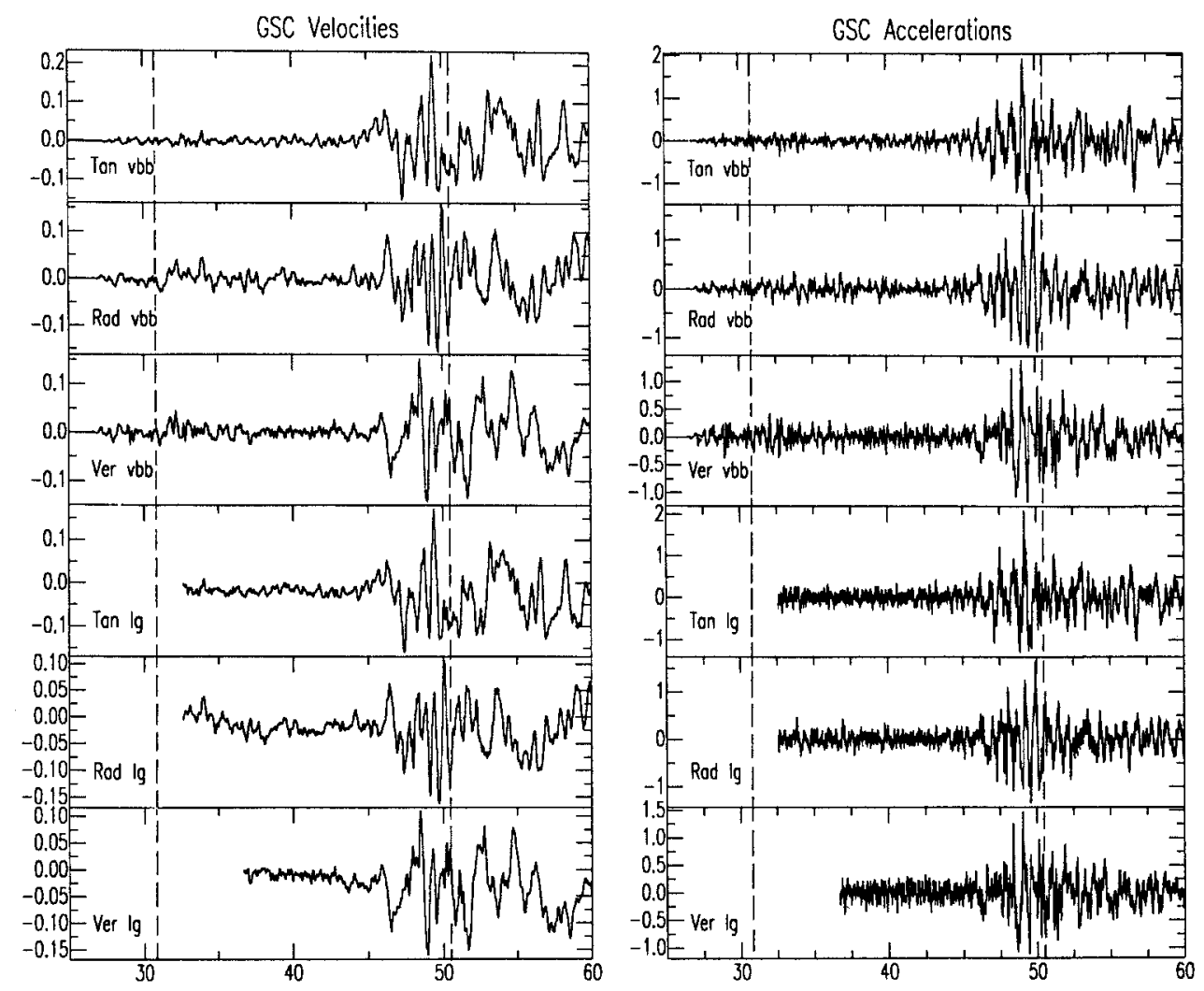

FIG. 4. Comparison of the observed velocities and accelerations at GSC.

adjustments in the crustal model, see the middle columns of synthetics. An overlay of these synthetics with the mainshock observations shows remarkable waveform agreement in all three passbands. Note that in the synthetics the phase $s P_{m} P$ is obvious on the vertical component, whereas the phase $s S_{m} S$ is strong on the tangential component as predicted by the radiation pattern. The same features are clear in the data as well. Note that the phase $s S_{m} S$ is slightly delayed in the data compared with the synthetic. A slight reduction in the upper crustal shear velocity would correct this feature, but model B presented in Table 2 does quite well in fitting the other three stations as discussed later.

The amplitudes of the synthetics displayed in Figure 8 are about 50\% larger than the mainshock observations. There are two reasons for this discrepancy. First, the amplitudes observed at PFO are smaller than those at the other stations relative to the synthetics used in the source inversion by about $25 \%$ (Fig. 2). This suggests that the receiver structure at PFO is basically harder and faster than at the other stations. The other reasons is that the shear velocities displayed in model B (Table 2) are lower than in model A which tends to amplify the surface motions by about $25 \%$. Thus, by slowing down the shear velocity we can model the observations with less moment, in this case $M_{0}=1.7 \times 10^{24}$ dyne $\mathrm{cm}$. Presumably, the enlargement of the TERRAscope array, now in progress, will help resolve this issue when the crust and receiver structures become better known. Note that the radial component is particularly sensitive to the receiver structure, as displayed in Figure 9, in which a soft surface layer 
ISA Velocities

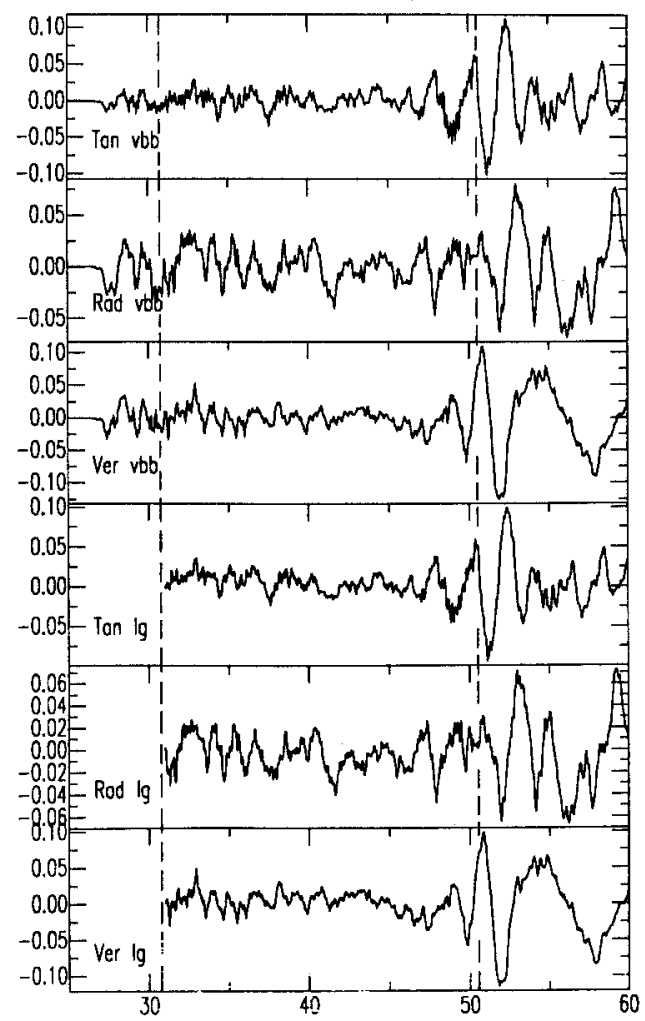

ISA Accelerotions

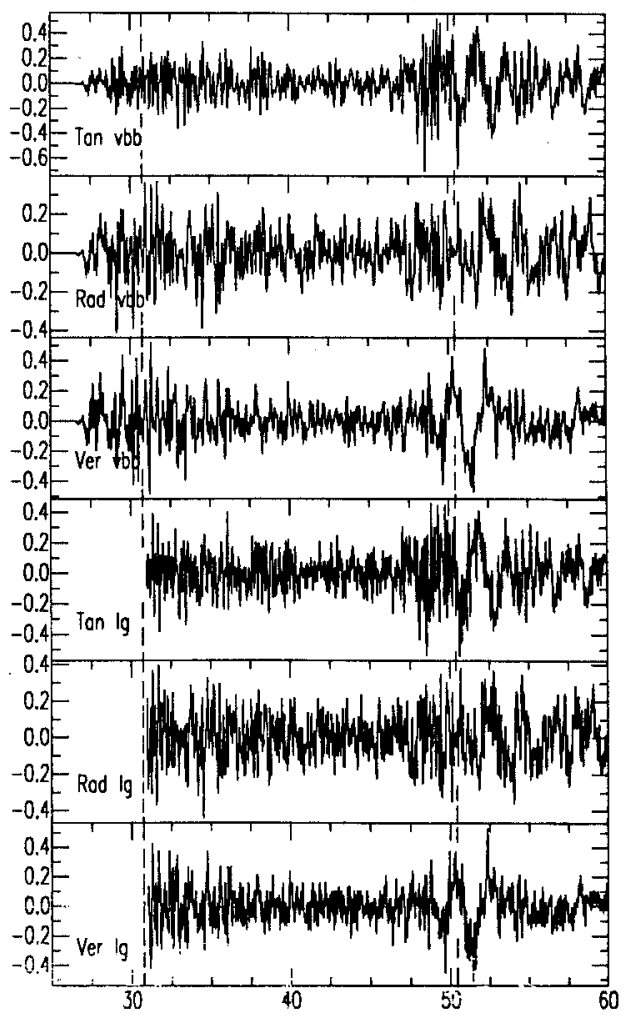

FIG. 5. Comparison of the observed velocities and accelerations at ISC.

has been included (see model $\mathrm{C}$ in Table 2). Such a layer increases the ratio of WASP to 3090 by about a factor of 2 .

Comparing the long period synthetic waveforms from the latter two models indicates the relative insensitivity of the long period synthetics to structure. Furthermore, by breaking down the contributions from the various layers, we can see that the shallow crustal structure dominates the longer period behavior with distance whereas the deeper structure controls the high-frequency arrivals. The evolution of this behavior with distance will be addressed later. We derived model $\mathrm{B}$ by making some adjustments in the shear velocities of model $\mathrm{A}$ based on examining particular generalized ray paths (Helmberger et al. 1992). Note that the previous synthetics have been generated by reflectivity, which produces complete solutions. Figures 10 and 11 display the evolution of the P-SV field as a function of distance and path. These synthetics are expressed in velocity so that they can be compared directly with data.

The first column of these figures displays the arrivals associated with the top layer. Two groups of arrivals develop, the first is dominated by $P$ and multiple $P-S V$ waves in which the main source of energy is the up-going SV ray, as displayed at the top of the figure. The longer period contributions of this control the first $15 \mathrm{sec}$ of the 3090 responses discussed earlier, and is derived essentially from energy traveling as $P$-head waves or refractions along the bottom of this waveguide. Similar types of motions are associated with the lower crustal 

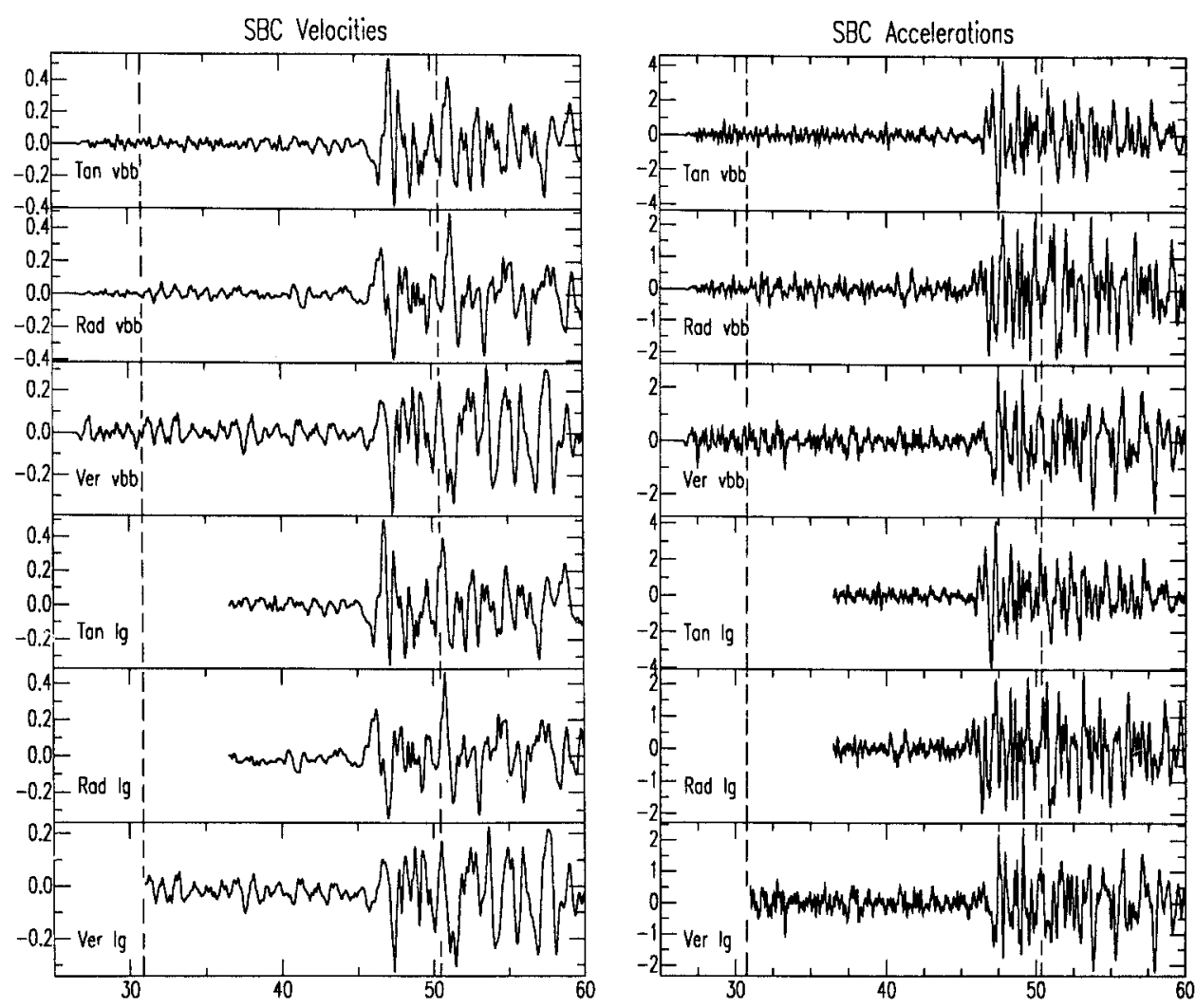

FIG. 6. Comparison of the observed velocities and accelerations at SBC.

waveguide (crust-mantle) where they are are referred to as $P L$ waves, (Helmberger and Engen, 1980). They appear to be quite insensitive to structure. Note that adding a shallow layer does not change the long period substantially, compare Figures 8 and 9 and see Dreger and Helmberger (1990).

The second group of arrivals in the lower traces of column one are produced by multiple $S V$ waves. They decay with distance rapidly because the upward transmission is coefficient is weak. Shallow $P L$ waves arrive as $P$-waves along the surface and tend to be the strongest on the radial, whereas the second group tends to be strongest on the vertical. This feature is well-defined in the broadband seismograms discussed earlier.

The second column of these figures contains the summation of column one plus arrivals that return from the lower crust as displayed. The latter have little effect at the closer distances. They contribute when critical angles are reached at $60 \mathrm{~km}$ for the Conrad and at $120 \mathrm{~km}$ for the Moho. Adding in the surface reflections ( $p P, s P, p S, s S$ ), third column, produces little effect on the vertical component except at the largest distance, at which $s S_{m} S$ becomes apparent. The phase $s P_{m} P$ is very apparent on the radial component.

A comparison of the observations in the velocity domain with the corresponding synthetics is given in Figure 12. These synthetics were generated with a reduced moment, $35 \%$ of the long period level, which reduces the amplitudes accordingly. Thus, the peak amplitude of the vertical component at PFO is 0.18 
VERTICAL

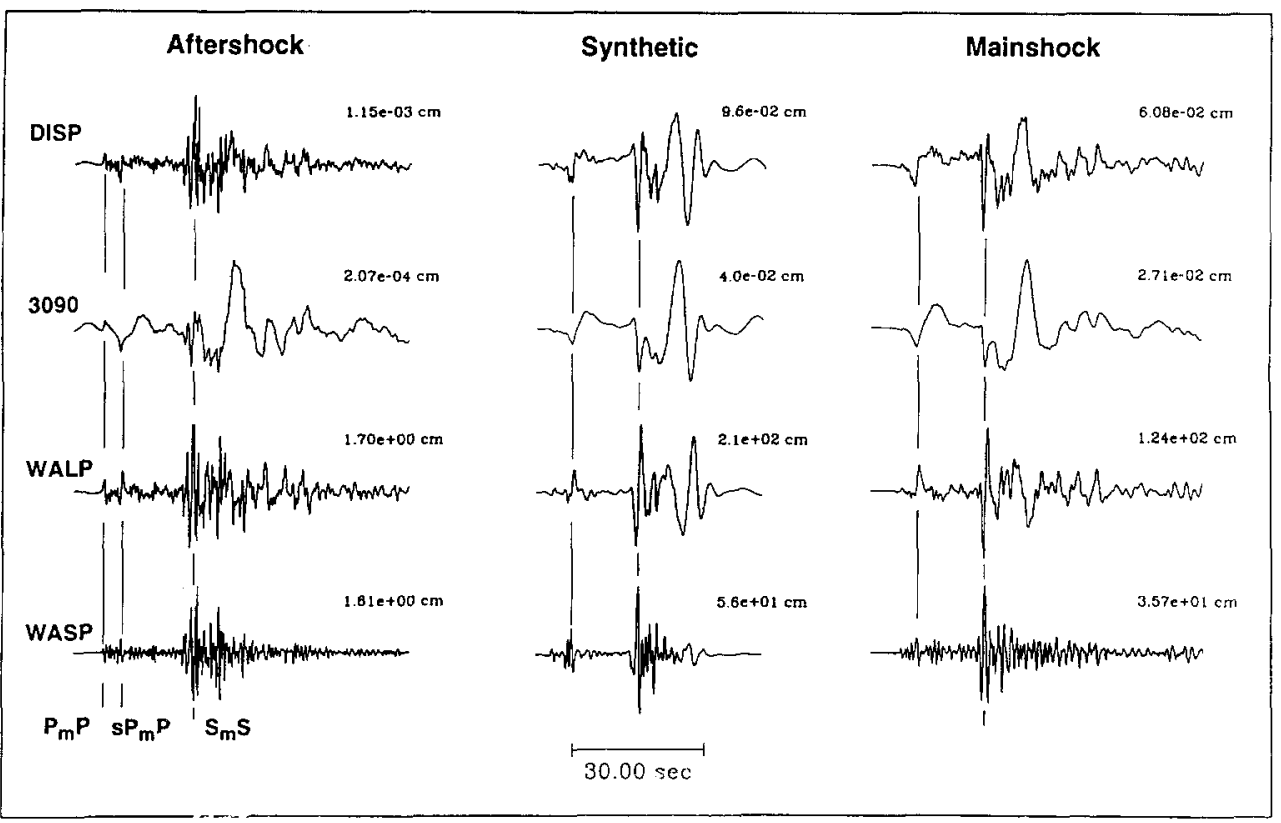

FiG. 7. Display of the vertical motions for the mainshock, aftershock, and synthetic (model B in Table 2) after the simulation of the various instrumental responses at station PFO. The Wood-Anderson responses, WALP ( $6 \mathrm{sec}$ torsion) and WASP $(0.8 \mathrm{sec}$ torsion) gain factors were included in the amplitudes.

TANGENTIAL

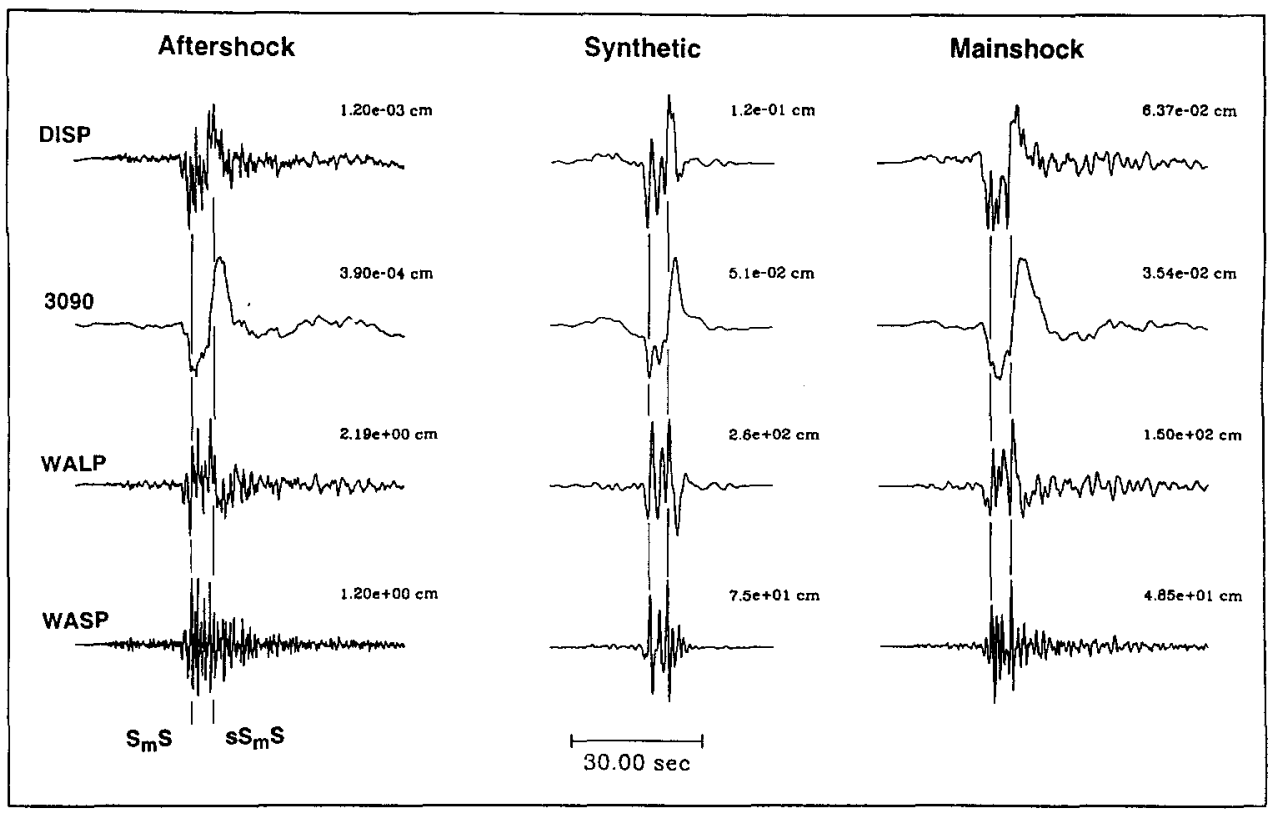

FiG. 8. Display of the tangential motions for the mainshock, aftershock, and synthetic (model B in Table 2) after the simulation of the various instrumental responses at station PFO. The Wood-Anderson responses, WALP ( 6 sec torsion) and WASP ( 0.8 sec torsion) gain factors were included in the amplitudes. 

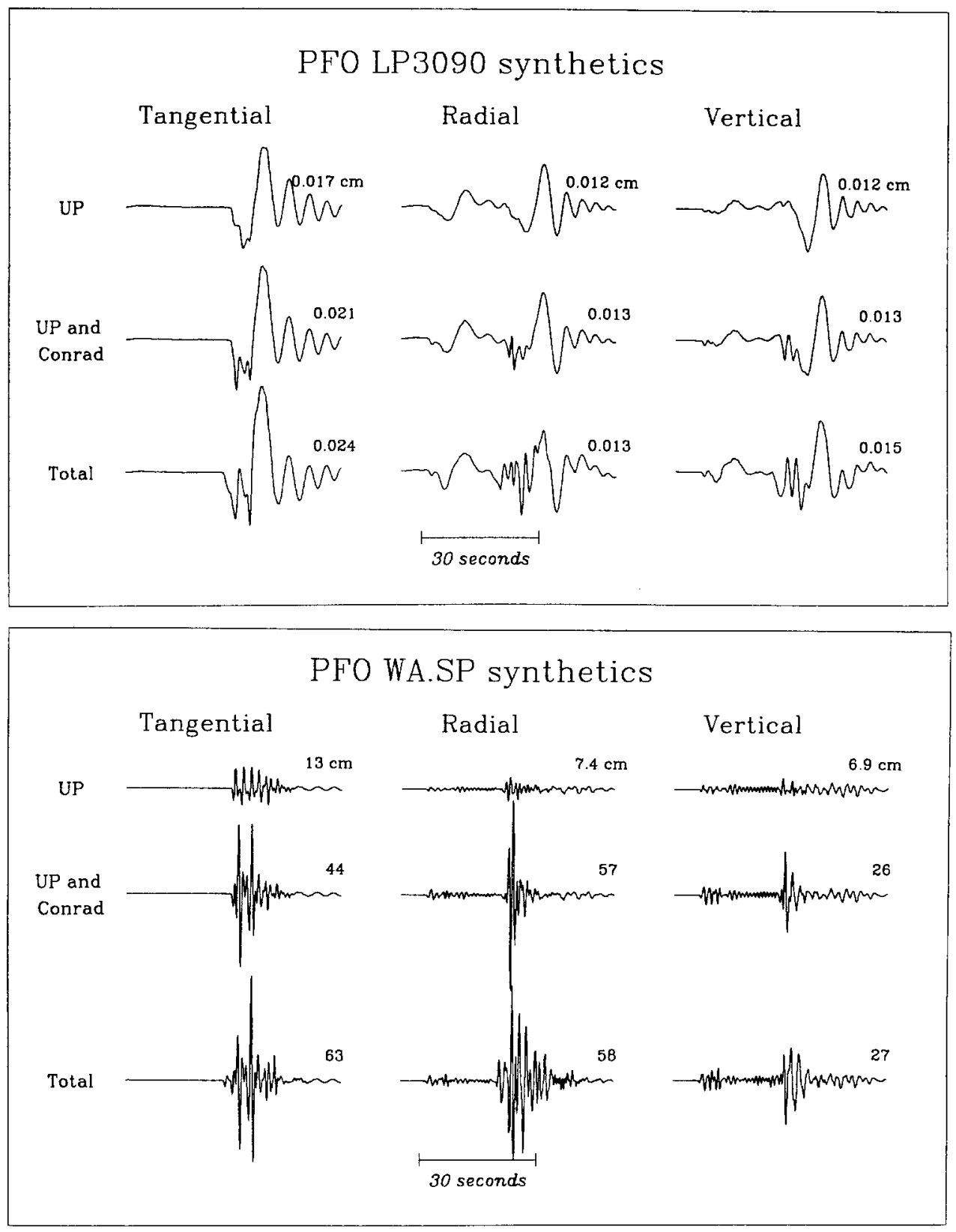

FIG. 9. Display of synthetics (model $\mathbf{C}$ in Table 2) indicating contributions from the upper waveguide relative to the entire model. The traces marked UP are appropriate for no layering below the source.

$\mathrm{cm} / \mathrm{sec}$ instead of 0.5 as in the earlier Figure 6. This reduced moment produces about the right level of motion at most stations except SBC, which is in the direction of rupture and is enhanced by directivity, (Dreger and Helmberger, 1992). Station ISA is both near a tangential node and spread out by directivity, a feature also apparent in waveshape, where it appears to have longer periods than the others. Still another difficulty at ISA is the lack of clean separation 


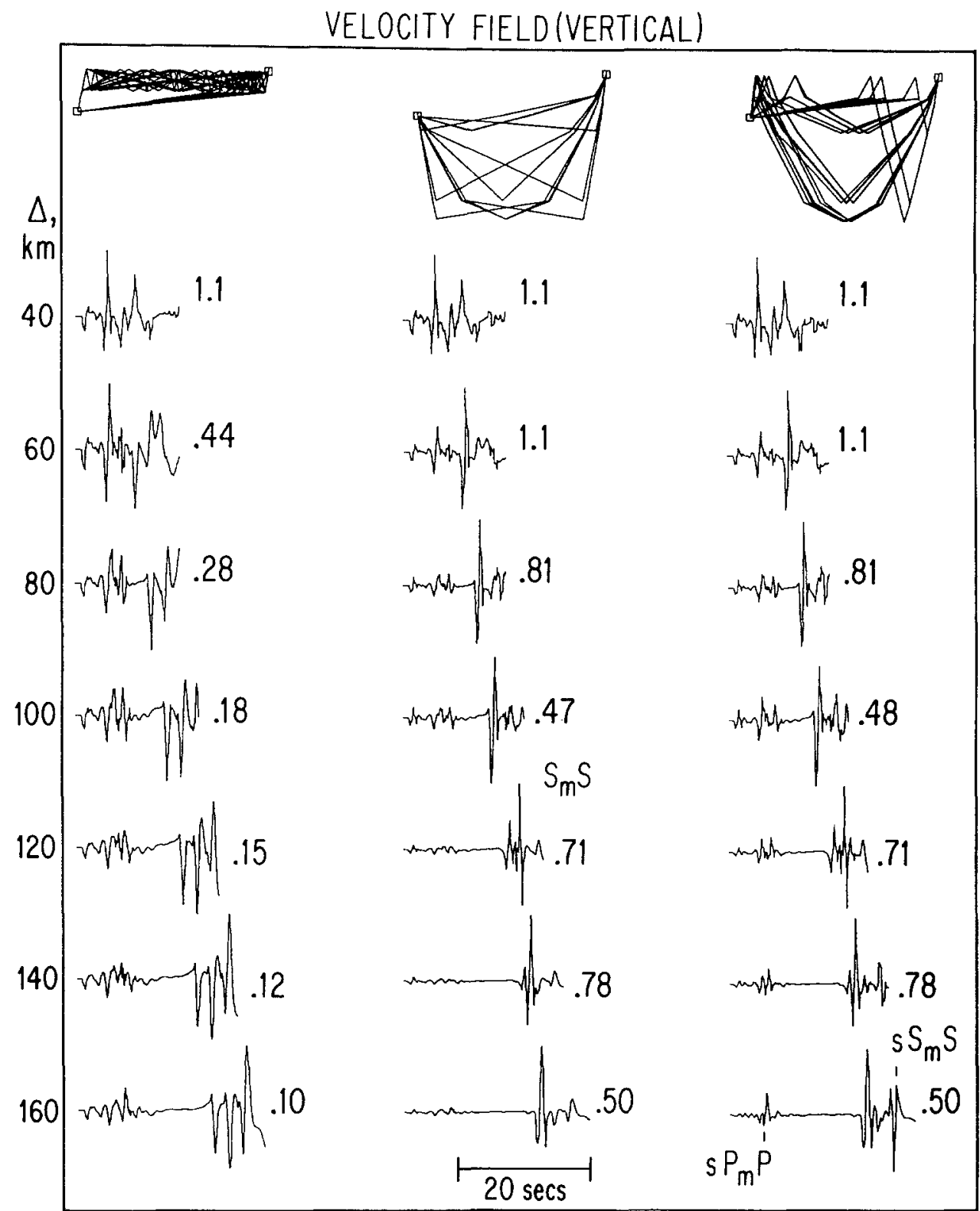

FIG. 10. Vertical component synthetics (GRT) as a function of distance and ray summation. The numbers indicate the peak amplitudes in $\mathrm{cm} / \mathrm{sec}$ where the $M_{0}$ was set at $2.4 \times 10^{24} \mathrm{ergs}$ for instances in which model B was used in computing the synthetics.

into the P-SV and SH systems of motions. Note that most of the stations rotate quite well, especially PFO, which also produces the best fit to the synthetics.

The drop in moment required to model the higher frequency waveforms, as in this case, has been noted in many studies. In particular, it has been discussed in Bent and Helmberger (1991) in which five events along the extension of the Transverse Ranges have been studied as a group. They find that the 1973 Point Mugu event, $M=6$, has the strongest teleseismic short period to long period ratio, roughly $90 \%$ of the long period moment also required to model the short 


\section{VELOCITY FIELD(RADIAL)}

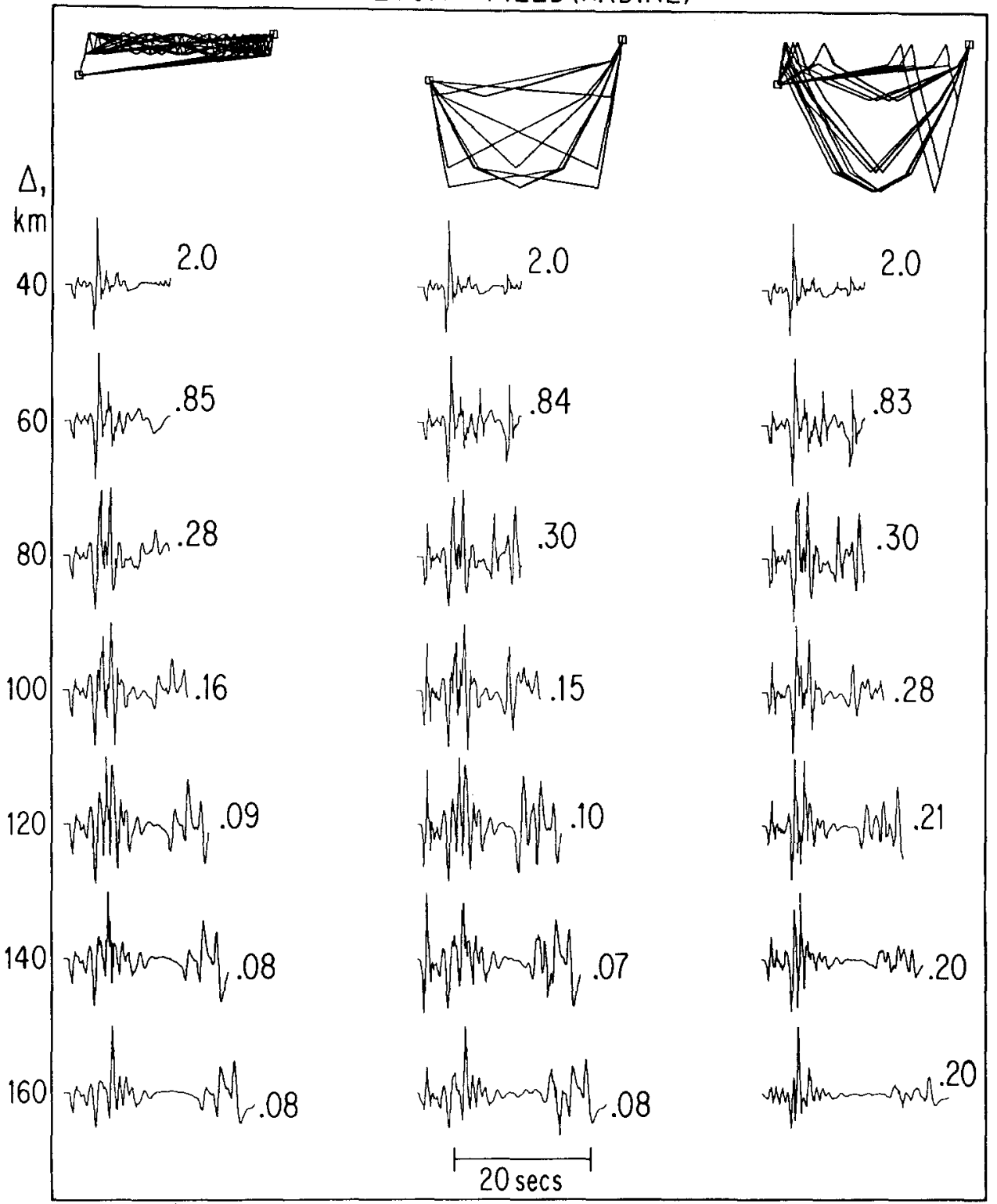

FIG. 11. Radial component synthetics (GRT) as a function of distance and ray summation for the same model. The numbers indicate the peak amplitudes in $\mathrm{cm} / \mathrm{sec}$ where the $M_{0}$ was set at $2.4 \times 10^{24}$ ergs.

period. The smallest ratio occurred for the Santa Barbara 1978 event, in which only $15 \%$ was required. Generally, this ratio has not been considered too meaningful, because the Earth's attenuation is not known to the precision necessary to uniquely determine the short period moment. However, in this case many of the paths are nearly identical, the relative differences between events are probably real.

A simple interpretation of these results can be given in terms of slip distribution, as recently concluded in a broadband study of the Upland event, $M=5.2$, 
PFO

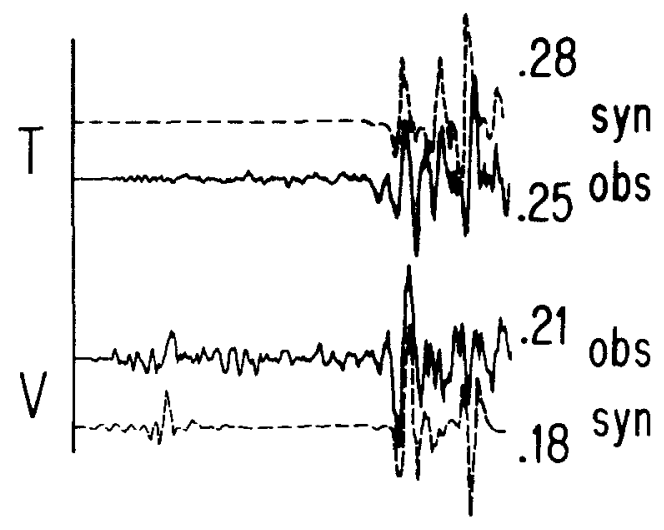

ISA

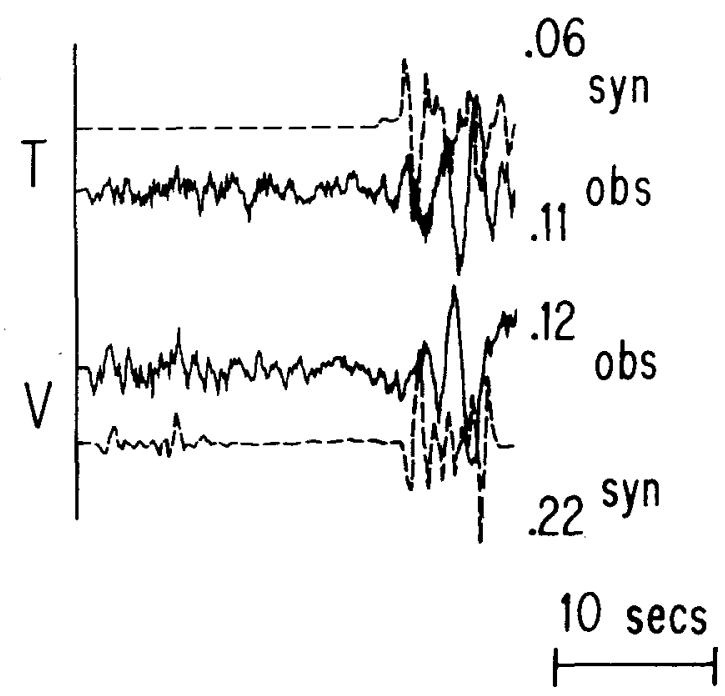

GSC

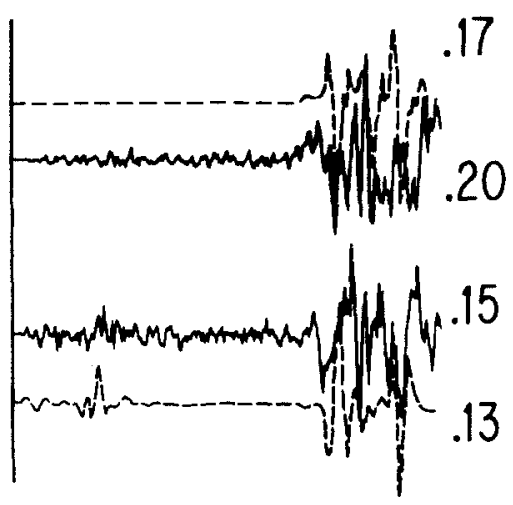

SBC

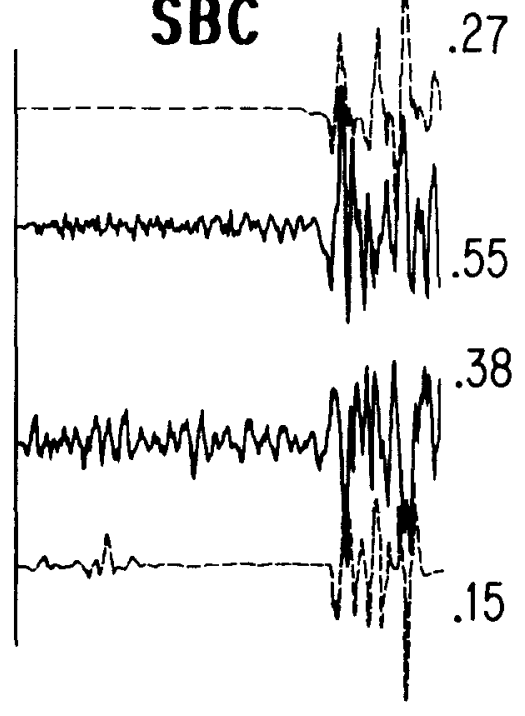

FIG. 12. Comparison of observed velocities for which peak amplitudes are given in $\mathrm{cm} / \mathrm{sec}$ Dotted lines indicate the timing of $s P_{m} P$ and $s S_{m} S$.

(Dreger and Helmberger, 1991b). They find that modeling the whole broadband waveforms of this event requires a faulting area of about $8 \mathrm{~km}^{2}$ with a high stress drop patch, $1 \mathrm{~km}^{2}$, which contains about $30 \%$ of the moment. Similar results were obtained for the Sierra Madre event from modeling the strong motion and teleseismic data (Wald, 1992). Wald concludes that a $12-\mathrm{km}^{2}$ area was required with a $3-\mathrm{km}^{2}$ patch at the center. His results seem quite compatible with our $35 \%$ value required in simulating the velocities. A detailed study of TERRAscope data from the Sierra Madre earthquake sequence, indeed, produces a distributed fault offset compatible with these results (Dreger and Helmberger, 1992).

Despite the many inconsistencies in modeling the detailed observed waveforms in Figure 12, it appears that the phase $s P_{m} P$ and $s S_{m} S$ are clearly 
observed in velocity, and consequently the lower crustal structure becomes the dominant path at these distances for short periods. Also, the close association in timing of these phases, between the observed velocities and accelerations, indicates that this path is the controlling strong motion at these distances. Thus, there must be a cross-over in distance at which diving energy paths begin to dominate the direct arrivals. Figure 10, discussed earlier, suggests that this occurs at about $50 \mathrm{~km}$, but this is influenced by many factors including the component, the radiation pattern, source depth, and the detailed nature of the crust. The latter problem will be addressed in the next section in which we introduce some complexities into the crustal waveguide.

\section{Numerical Scattering Experiments and Attenuation}

The introduction of laterally varying structure causes considerable interference between the three ray-groups discussed earlier. This is especially true at mid ranges, 50 to $90 \mathrm{~km}$, in which the summation has about the same amplitude as each individual group (see Figures 10 and 11). In this section, we discuss the theoretical results from models containing random scatterers embedded in the various layers. We are particularly concerned with the development of high-frequency arrivals and their amplitude decay with distance.

The model setup is displayed in Figure 13. We investigated four cases with variation allowed in particular layers: RMOHO (thin, $3 \mathrm{~km}$, layer at the top of the mantle), RSURF (surface layer only, $4 \mathrm{~km}$ ), RBOTH (both layers at the surface and at the top of the mantle), and RALL (variation throughout all layers, total $31 \mathrm{~km}$ ). The scattering model follows the scheme discussed by Frankel and Clayton (1984), in which a Gaussian correlation function is imposed on a random medium. We have modified this scheme to permit the correlation distance to differ between the $x$ and $z$ directions. We note here that total coda may be underestimated, as Frankel and Clayton (1986) have shown that a self-similar correlation function is preferred to generate sufficient coda. However, this affects primarily higher frequencies (up to $30 \mathrm{~Hz}$ ), whereas we consider nothing above $4 \mathrm{~Hz}$ in these finite difference results. Note that the difference in the nature of the $\mathrm{SH}$ and $\mathrm{P}-\mathrm{SV}$ systems requires different time

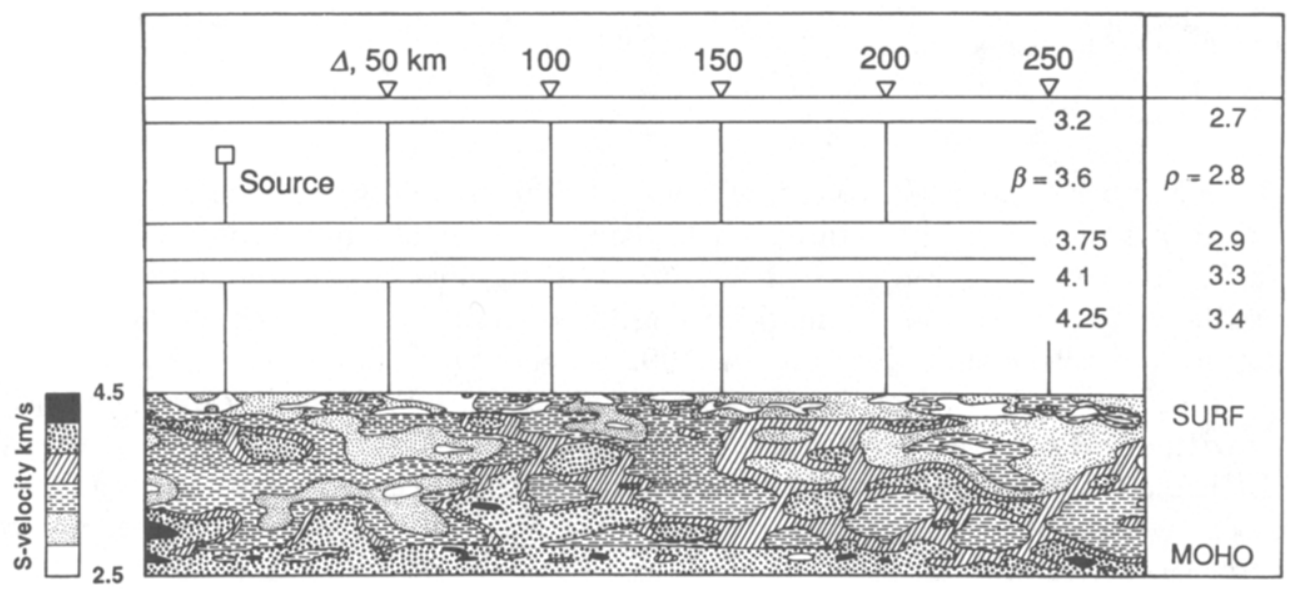

FIG. 13. Diagram displaying crustal heterogeneity with layers containing up to $20 \%$ velocity anomalies. 
steps and grid spacings. We used $0.2 \mathrm{~km}$ for $P-S V$ and 0.25 for $S H$, with steps of $0.015625 \mathrm{sec}$ and $0.025 \mathrm{sec}$, respectively. The variance is set for the $P$-wave velocity and is proportional for the $S$-wave velocity, whereas the density variance is $30 \%$ of the proportional variance. The variances and correlation distances used are as follows. For the surface layer, the RMS variance is 0.4 $\mathrm{km} / \mathrm{sec}$ and the correlation distances are $5 \mathrm{~km}$ in $x$ and $15 . \mathrm{km}$ in $z$. For the mantle layer, variance is $0.3 \mathrm{~km} / \mathrm{sec}$ and the correlation distances are $5 \mathrm{~km}$ in $x$ and $1.5 \mathrm{~km}$ in $z$. For the body of the crust in RALL, the variance is 0.5 $\mathrm{km} / \mathrm{sec}$, and the correlation distances are $12.5 \mathrm{~km}$ in $x$ and $5 \mathrm{~km}$ in $z$. The RMS variance is up to $10 \%$, and the peak variations produced are up to $20 \%$ of average velocities. The position and form of the variations are indicated in Figure 13. Variations of this size have been suggested by Frankel and Clayton (1984), and others and are probably on the high side based on the stability of observed crustal arrivals.

The complete wave field for these models was generated with the finitedifference method for ranges from 50 to $275 \mathrm{~km}$ with frequencies up to about 2 $\mathrm{hz}$. The technique used in this calculation is discussed in Helmberger and Vidale (1988), Vidale and Helmberger (1987). It is based on the expansion of the complete $3 \mathrm{D}$ solution of a dislocation source in asymptotic form, which provides for the separation of the motions into SH and P-SV systems of motion. Closeformed expressions appropriate for finite-difference source excitations are derived for the three fundamental fault types, requiring separate finite-difference runs. Only the strike-slip case will be discussed, which conveys the principal effects of including scatterers on the waveforms.

Results for the P-SV system are displayed in Figures 14 and 15. Two cases are compared: the case of uniform layered crust (RMOHO) and shallow scatterers (RSURF). These results are displayed broadband, and through a WoodAnderson instrument.

The synthetics appropriate for model RMOHO display many of the characteristics of those models discussed earlier. Note that the shallow structure dominates the motions until about $100 \mathrm{~km}$, at which time the Moho reflection becomes prominent. This feature is particularly prevalent at WASP, in which the amplitude increases substantially near $100 \mathrm{~km}$. Note that $s S_{m} S$ is easily identified starting at about $140 \mathrm{~km}$. The generation of these Moho arrivals develops sooner in distance in this particular model than in other models because the crust is slightly thinner. The synthetics for the RSURF model are more interesting but show the same basic behavior. When WALP responses are constructed from these two models, we obtain nearly identical results. However, WASP synthetics for model RSURF show considerably more complexity associated with up-going SV energy than do those for model RMOHO, and makes the presence of the Moho arrivals less dramatic except for the phase $s P_{m} P$. The extended $S$-wavetrain at high frequency looks like many observed records in which they are conventionally called $\mathrm{Lg}$.

A sample of the SH synthetics for all the models is displayed in Figure 16. It becomes difficult to interpret these complex waveforms because we can no longer decompose the waveform into subgroups, although we can still identify some of the more important phases such as $S_{m} S$ and $s S_{m} S$. A brief review of Figure 16 indicates that $s S_{m} S$ becomes strong near $200 \mathrm{~km}$, and $S_{m} S$ and $s S_{m} S$ are particularly obvious at ranges of 170 and 185 in the first three columns. Direct $S_{m} S$ becomes weaker in the most severe case (right column). 


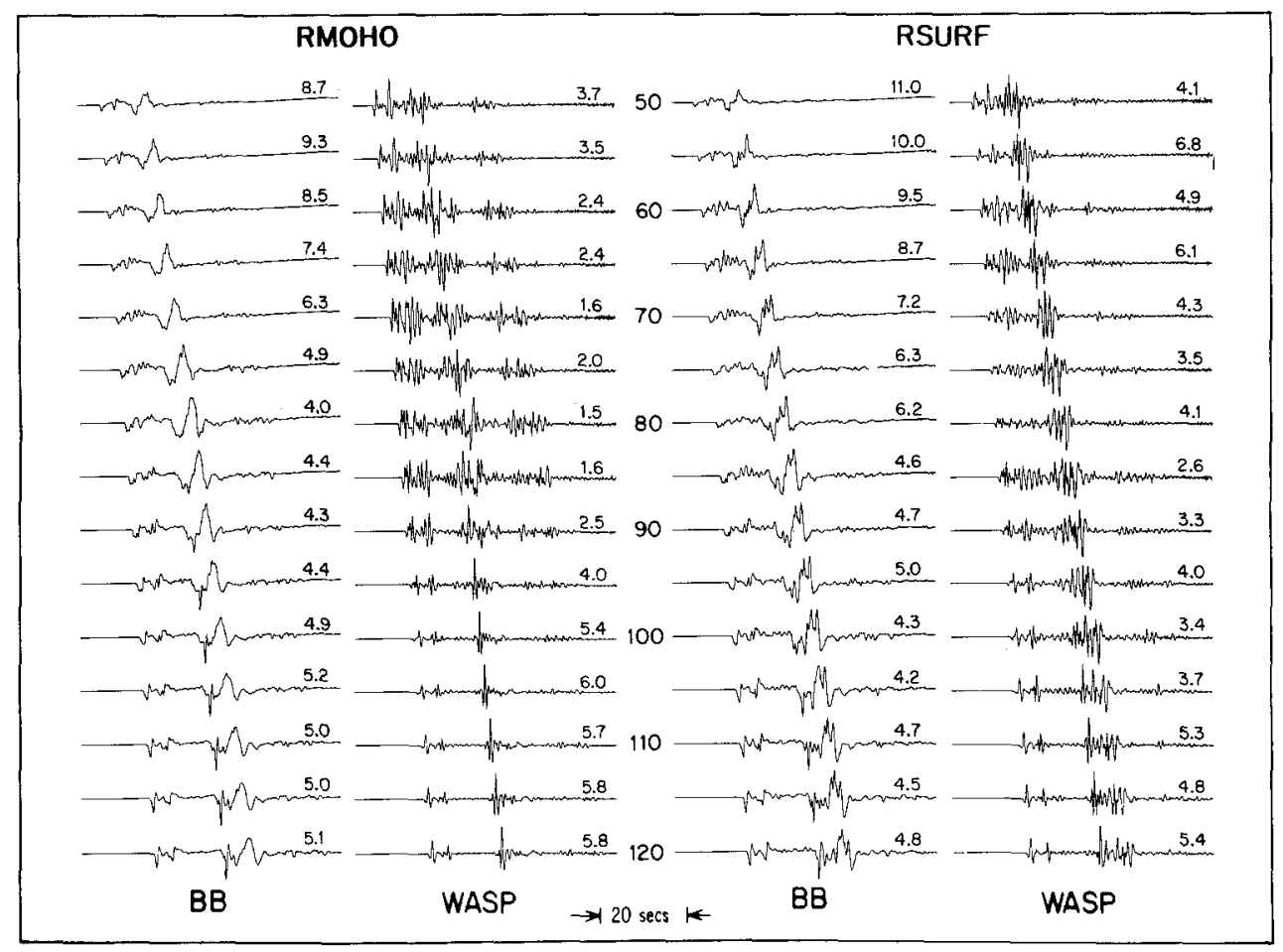

Fig. 14. Profiles of synthetics from 50 to $120 \mathrm{~km}$ comparing a plane-layered crust (RMOHO) with a model with scatterers in the upper layer (RSURF). The motions are simulated broadband (BB) and with respect to a Wood-Anderson instrument. Peak amplitudes are indicated above each trace in $\mathrm{cm}$.

Apparently, as the ray paths flatten they become more sensitive to lateral variation, as one would expect, and the multiples that travel more vertically become increasingly important.

The broadband SH responses of Figure 16 show considerable modulation in amplitude (see Figure 17). Included in this figure is a $(1 / R)$ reference which is commonly assumed in simulation techniques, (Chin and Aki, 1991). This would correspond to a direct arrival in halfspace, or would be expected for a model with a smooth velocity increase with depth. The direct arrival attenuates much faster in the models presented in this paper as compared with models in other papers because of the effects caused by the thick low-velocity layer near the surface. The small flattening that occurs near $60 \mathrm{~km}$ is caused by the strength of the first multiple or higher mode Love waves. The increased amplitude near $100 \mathrm{~km}$ is caused by the lower crustal transition zone and the sharpness of the Moho. The strong arrival at the range of $105 \mathrm{~km}$ in the full-scattering model, RALL, is caused by constructive interference between the Moho reflection and first multiple in the top layer (Love wave). In general, the strong scattering introduced in this exercise was sufficient to obscure the moho reflection, but the possibility of large motions near the cross-over distance appears difficult to avoid.

There are obviously many other reasons for amplitude fluctuations other than those displayed in Figure 17, such as source radiation patterns, source duration 


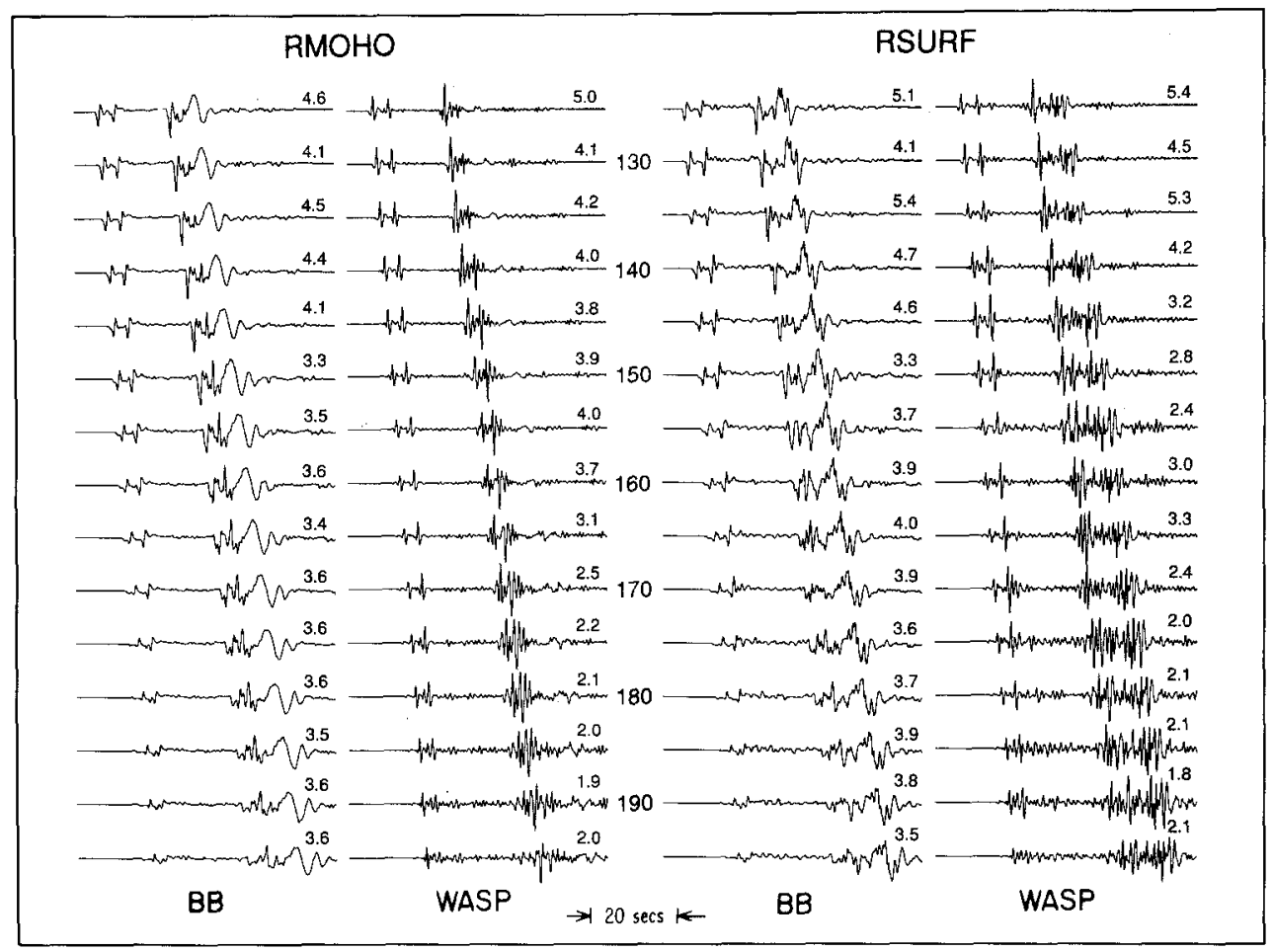

FIG. 15. Continuation of Figure 14 from 125 to $195 \mathrm{~km}$.

and complexity, mini-basin structures, nonlinear behaviors, and site-conditions. Many of these features are discussed in the special Loma Prieta issue (Hanks and Kruwinkler, 1991) and cannot be neglected in assessing strong motion hazards.

\section{CONCLUSIONS}

We have reviewed the broadband observations of the recent Sierra Madre earthquake in terms of displacement, velocity, and acceleration on the TERRAscope array. We found that the depth phases $s P_{m} P$ and $s S_{m} S$ are apparent in velocity and acceleration at four stations near $160 \mathrm{~km}$. These phases are less apparent at longer periods, in which the upper crustal waveguide still dominates their behavior. These features can be modeled in displacement and velocity, as demonstrated, and require relatively slow shear velocities in the top $5 \mathrm{~km}$ of the crust. This shallow zone has a dramatic effect on the rapid decay of direct $S$ with distance and probably contributes to its rather unstable observed behavior in that numerical results from models containing shallow scatterers predict irregular behavior. Beyond the cross-over distance, the lower crust dominates and appears to return relatively clear phases, even after adding scatterers to the crustal models. Essentially, pulses following ray paths travelling more vertically remain less scattered than those travelling more horizontally. Thus, our numerical results, in conjunction with the broadband observations, indicate that directivity may be more apparent in $S_{m} S$ and $s S_{m} S$ than in direct arrivals. 
FD with Random Media Reducing V=3.90

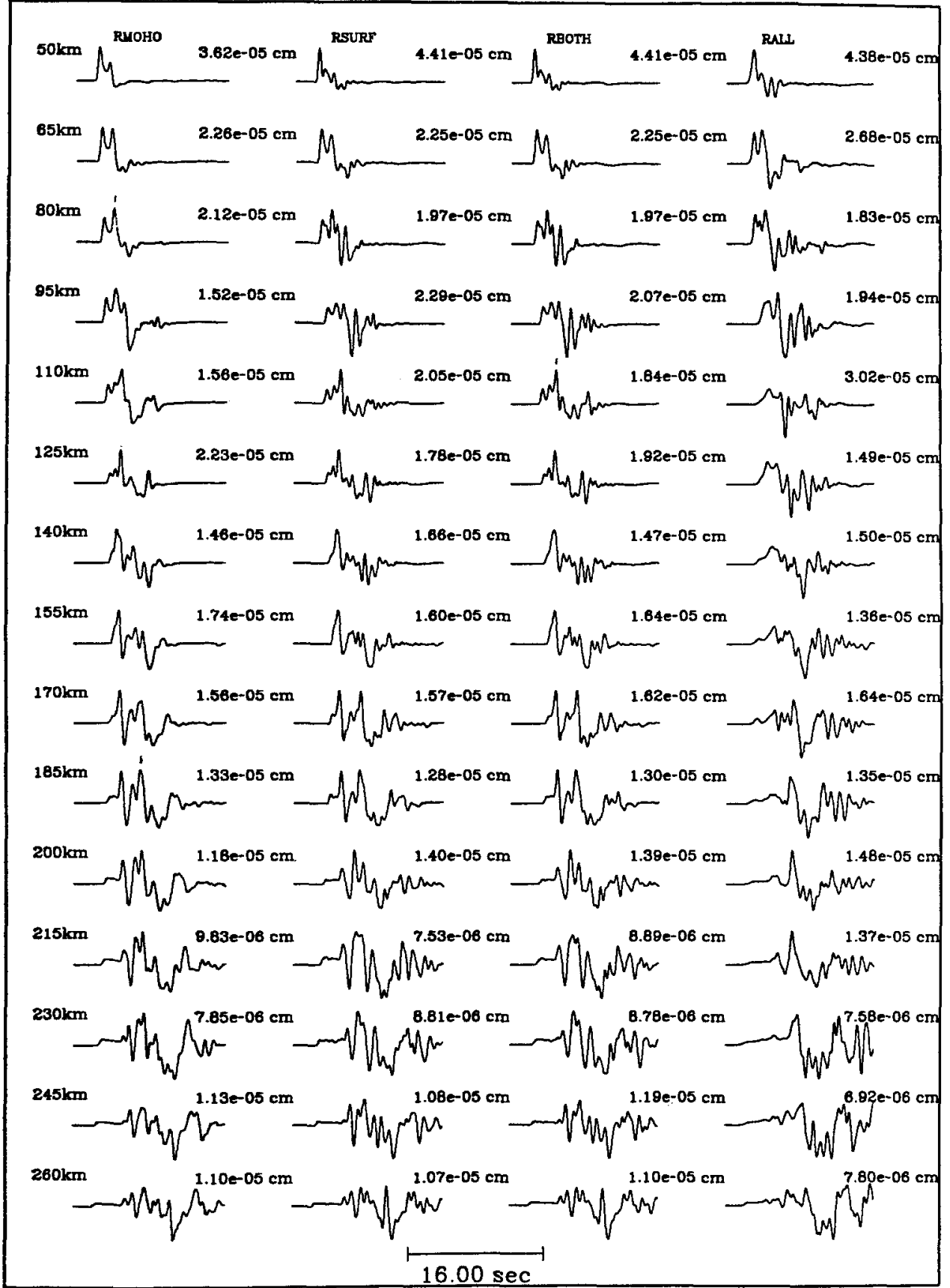

Fig. 16. Comparison of $\mathrm{SH}$ broadband synthetics for the various models along a profile from 50 to $260 \mathrm{kms}$. Peak amplitudes are given in $\mathrm{cm}$. 


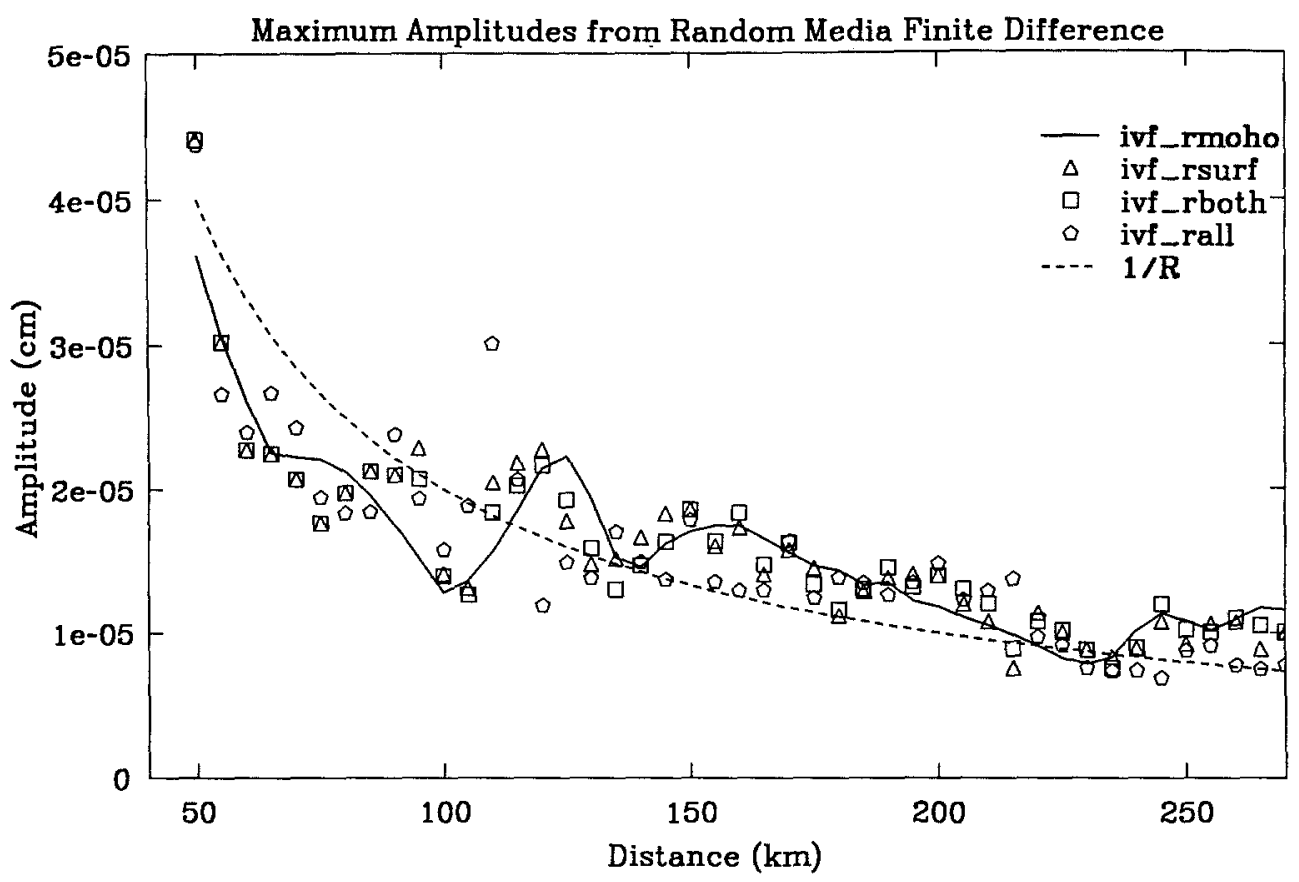

FIG. 17. Attenuation of amplitude decay with distance showing the effects of the various models. A $(1 / R)$ curve is included for comparison. The symbols indicate the peak amplitudes obtained from Figure 16 after convolution with the Wood-Anderson instrument.

In short, we have demonstrated the role of crustal structure in influencing strong motions and suggest that modern broadband data may contribute to the resolution of the many issues associated with their generation.

\section{ACKNOWLEDGMENTS}

This research was supported by U.S.G.S. contract 14-08-001-G1872 and contribution No. 5143, Division of Geological and Planetary Sciences, California Institute of Technology, Pasadena, California, 91125.

\section{REFERENCES}

Bent, A. L. and D. V. Helmberger (1991). Seismic characteristics of earthquakes along the offshore extension of the western transverse ranges, California, Bull. Seism. Soc. Am. 81, 399-422.

Campbell, K. W. (1991). An empirical analysis of peak horizontal acceleration for the Loma Prieta, California, earthquake of 18 October 1989, Bull. Seism. Soc. Am. 81, 1838-1858.

Chin, B. H. and K. Aki (1991). Simultaneous study of source, path, and site effects on strong ground motion during the 1989 Loma Prieta earthquake, Bull. Seism. Soc. Am. 81, 1859-1884.

Dreger, D. S. and D. V. Helmberger (1990). Broadband modeling of local earthquakes, Bull. Seism. Soc. Am. 80, 1162-1179.

Dreger, D. S. and D. V. Helmberger (1991a). Source parameters of the Sierra Madre earthquake from regional and local body waves, Geophys. Res. Lett. 18, 2015-2018.

Dreger, D. S. and D. V. Helmberger (1991b). Complex faulting deduced from broadband modeling of the 28 February 1990 Upland earthquake $\left(\mathrm{M}_{\mathrm{L}}=5.2\right)$, Bull. Seism. Soc. Am. 81, 1129-1144.

Dreger, D. S. and D. V. Helmberger (1992). Broadband observation of rupture directivity for the 1991 Sierra Madre earthquake, Bull. Seism. Soc. Am. (in press).

Frankel, A. and R. W. Clayton (1984). A finite-difference simulation of wave propagation in two-dimensional random media, Bull. Seism. Soc. Am. 74, 2167-2186.

Frankel, A. and R. W. Clayton (1986). Finite difference simulations of seismic scattering: implications for the propagation of short-period seismic waves in the crust and models of crustal heterogeneity, Journal Geophysical Research, 90, 6465-6489. 
Hanks, T. C. and H. Kruwinkler (1991). The 1989 Loma Prieta earthquake and its effects: introduction to the special issue, Bull. Seism. Soc. Am. 81, 1415-1423.

Helmberger, D. V. and G. R. Engen, (1980). Modeling the long-period body waves from shallow earthquakes at regional ranges, Bull. Seism. Soc. Am. 70, 1699-1714.

Helmberger, D. V. and John E. Vidale (1988). Modeling strong motions produced by earthquakes with two-dimensional numerical codes, Bull. Seism. Soc. of Am. 78, 109-121.

Helmberger, D., R. Stead, P. Ho-Liu, and D. Dreger (1992). Broadband modeling of regional seismograms; Imperial Valley to Pasadena, Geophys. J. Intern., 110, 42-54.

McGarr, A., M. Celebi, E. Sembera, T. Noce, and C. Mueller (1991), Ground motion at the San Francisco International Airport from the Loma Prieta earthquake sequence, 1989, Bull. Seism. Soc. Am. 81, 1923-1944.

Somerville, P. and J. Yoshimura (1990). The influence of critical Moho reflections on strong ground motions recorded in San Francisco and Oakland during the 1989 Loma Prieta earthquake, Geophys. Res. Lett. 17, 1203-1206.

Vidale, J. E. and D. V. Helmberger (1987). Seismic Strong Motion Synthetics, in Computational Techniques 4, Academic Press, Inc., Orlando, Florida, 267-317.

Wald, L. A., L. K. Hutton, L. L. Jones, D. D. Given, K. Douglass, J. Mori, E. Hauksson, and H. Kanamori, The Southern California Network Bulletin, January-December 1991.

Wald, D. J. (1992). Strong Motion and Broadband Teleseismic Analysis of the 1991 Sierra Madre, California, earthquake, Journal Geophysical Research 97, 11,033-11,046.

Zhao, L. S. and D. V. Helmberger, (1993). Source estimation from broadband regional seismograms, submitted BSSA.

SEISMOLOGICAL LABORATORY

CALIFORNia Institute of TECHNOLOGY

Pasadena, Californta 91125

Manuscript received 18 August 1992 